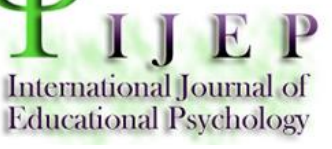

Hipatia Press

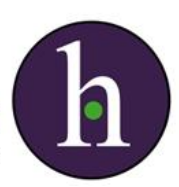

Instructions for authors, subscriptions and further details:

http://ijep.hipatiapress.com

\title{
Probing the Underlying Structure of Modern Expectancy-Value Theory in Multicultural Education: A Bayesian Exploratory Factor Analysis
}

\author{
Yan Yang and Diana Mindrila ${ }^{1}$ \\ 1) University of West Georgia, United States of America \\ Date of publication: February $24^{\text {th }}, 2020$ \\ Edition period: February 2020 - June 2020
}

To cite this article: Yang, Y., \& Mindrila, D. (2020). Probing the underlying structure of modern expectancy-value theory in multicultural education: Bayesian exploratory factor analysis. International Journal of Educational Psychology, 9(1), 55-81. doi: 10.17583/ijep.2020.4261

To link this article: http://dx.doi.org/10.17583/ijep.2020.4261

\section{PLEASE SCROLL DOWN FOR ARTICLE}

The terms and conditions of use are related to the Open Journal System and to Creative Commons Attribution License (CC-BY). 


\section{Probing the Underlying Structure of Modern Expectancy-Value Theory in Multicultural Education: A Bayesian Exploratory Factor Analysis}

Yan Yang and Diana Mindrila

University of West Georgia

\section{Abstract}

Expectancy-Value (EV) theory has been widely used in a plethora of domains except for multicultural education, a distinct and critical field in many countries due to increasing student diversity. In light of the domain-specific nature of the EV theory and the discrepancy between the theoretical framework and empirical models found in previous studies, the purpose of the present study was to explore the factors of the EV theory in multicultural education. Participants were 187 college students who completed the Multicultural Expectancy-Value Scale (EVS). Exploratory factor analysis (EFA) with Bayes estimation and GEOMIN rotation resulted in two factors: Value and Expectancy. The two factors had a positive significant correlation of .42, $\mathrm{p}<.001$. Participants with a Master's or Doctoral degree had significantly higher Expectancy beliefs in multicultural education than those with a Bachelor's degree $(\mathrm{t}(47.727)=-2.90, \mathrm{p}<.01)$. Although our finding was consistent with the major tenets of the theory that expectancy and value beliefs are two primary motivating factors, it did not fully support the theoretical model, indicating a more parsimonious factor structure may be more appropriate. The distinct factor model in our study suggests a need for further research in examining the structural validity of the EV theory in multicultural education.

Keywords: Expectancy-Value (EV) theory, multicultural education, Bayesian exploratory factor analysis, value, expectancy. 


\section{Probando la Estructura Subyacente de la Teoría Moderna del Valor de la Expectativa en la Educación Multicultural: Un Análisis Factorial Exploratorio Bayesiano}

\section{Yan Yang and Diana Mindrila}

University of West Georgia

\section{Resumen}

La teoría de la expectativa de valor (EV) se ha utilizado ampliamente en una gran cantidad de dominios, excepto para la educación multicultural, un campo distinto y crítico en muchos países debido al aumento de la diversidad estudiantil. A la luz de la naturaleza específica del dominio de la teoría EV y la discrepancia entre el marco teórico y los modelos empíricos encontrados en estudios anteriores, el propósito del presente estudio fue explorar los factores de la teoría EV en la educación multicultural. Los participantes fueron 187 estudiantes universitarios que completaron la Escala de valor de expectativa multicultural (EVS). El análisis factorial exploratorio (EPT) con la estimación de Bayes y la rotación de GEOMIN dio como resultado dos factores: valor y expectativa. Los dos factores tuvieron una correlación significativa positiva de .42, $\mathrm{p}<.001$. Los participantes con maestría o doctorado tenían una expectativa significativamente más alta $(\mathrm{t}(47.727)=$ - 2.90, p <.01) creencias en la educación multicultural que aquellos con un título de bachiller. Aunque nuestro hallazgo fue consistente con los principios principales de la teoría de que la expectativa y las creencias de valor son dos factores motivadores principales, no apoyó completamente el modelo teórico, lo que indica que una estructura de factores más parsimoniosa puede ser más apropiada. El modelo de factor distinto en nuestro estudio sugiere la necesidad de más investigación para examinar la validez estructural de la teoría EV en la educación multicultural.

Palabras clave: Teoría del valor de la expectativa (EV), educación multicultural, análisis factorial exploratorio bayesiano, valor, expectativa. 


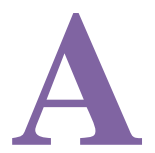

s an important motivation approach to learning, ExpectancyValue (EV) theory (Eccles \& Wigfield, 2002) has been widely used in a plethora of fields including physical education (Grasten, 2016), music education (Burak, 2014), and STEM education (Lykegaard \& Ulriksen, 2016), all of which consistently show that higher expectancy of success and task values tend to result in more motivation, persistence, resilience, and success; however, to date, no known studies to date have examined the utility of EV theory in multicultural education. To meet the needs of increasing student diversity and globalization and promote a more equitable and just education, multicultural education has become essential in the United States for almost four decades (Banks, 1981) as well as in other countries such as Malaysia and UK (Phoon, Abdullah, \& Abdullah, 2013; Sleeter, 2018). Multicultural education is defined as a field of study on various diversity topics including but not limited to race and ethnicity, socioeconomic status, language, religion, and sexual orientation to increase educational equity for all students (Banks \& Banks, 1995). It focuses on celebrating cultural differences while also recognizing the need to challenge all forms of discrimination. Given the proven important roles of EV theory in many disciplines as documented in prior studies aforementioned, it merits research on its utility in multicultural education due to its domain specific nature (Eccles et al., 1983). Therefore, this study was an attempt to bridge the gap between motivation and multicultural education by exploring the structure of EV theory in the context of multicultural education.

Previous study results suggested a discrepancy between the EV theoretical framework and empirical models (Lykkegaard \& Ulriksen, 2016; McCormick \& McPherson, 2007; Trautwein et al., 2012). For example, in a study on students' longitudinal reflections about their choice of a STEM education, Lykkegaard and Ulriksen (2016) questioned the validity of the EV model as it did not agree with their qualitative results or predict students' choice considerations. In another study ( $\mathrm{Au}, 2006)$, only interest and utility value were found to fit the sample population of 97 students aged 7 to 11 from three elementary schools, hence failure to support the EV model. Given the domain-specific nature of the EV model and the disagreeing empirical factor solutions in previous research findings, the purpose of the study was to explore the underlying structure of the EV theory in multicultural education. 


\section{Expectancy-Value Theory}

Proposed by Eccles and colleagues (e.g., Eccles et al., 1983; Eccles \& Wigfield, 1995, 2002), EV theory was initially situated in mathematics achievement with the proposition that student motivation is jointly influenced by their expectancy of success and values they attached to the task. Eccles et al (1983) defined and measured expectancy of success as the beliefs of children about how well they can do on a particular task. Although it is empirically related to children's ability beliefs, Wigfield and Eccles (2000) argued that it is conceptually different, in that expectancy of success focused more on the future than ability beliefs. The other major component of the theory is task values, consisting of attainment value, intrinsic/interest value, utility value, and cost (Eccles et al., 1983). Attainment value addresses the personal importance of doing well on a task based on one's identity. It refers to how important it is for a student to perform well on the task. Interest value is the enjoyment one gets from doing the task. In the context of multicultural education, it concerns personal enjoyment and satisfaction that a student derives from learning about human diversity. Utility value refers to the usefulness of the task to reach the proximal and distal goals, which is prone to the extrinsic value of learning. Finally, cost is conceptualized as a negative component of task value: the negative aspects of engaging in a task or activity, including anxiety, fear, efforts needed to succeed, and lost opportunities to perform other tasks or activities (Burak, 2014). According to the EV theory (Wigfield \& Eccles, 2000), expectancy and values are not only assumed to directly influence achievement, but also performance, effort, and persistence.

As a motivational approach to education, expectancy and value beliefs have been widely used in a variety of disciplines such as STEMS education (Abraham \& Barker, 2015; Andersen \& Ward, 2014), music education (McCormick \& McPherson, 2007; Wigfield, 1997), physical education (Zan, Lee, \& Harrison, 2008; Zhu, Sun, Chen, \& Ennis, 2012), K-12 education particularly in math, English and reading literacy (Durik, Vida, \& Eccles, 2006), physics (Abraham \& Barker, 2015), and gifted education (Rodgers, 2008). EV beliefs have been shown to predict student enrollment (Abraham \& Barker, 2015), STEMS persistence (Andersen \& Ward, 2014), choicemaking (Durik, Vida, \& Eccles, 2006; Guo et al., 2015), and career plans (Jones et al., 2010; Lauermann, Tsai, \& Eccles, 2017). Further, Trautwein and colleagues (2012) found that expectancy and value beliefs predicted the 
students' performances in math and English differentially, echoing that the $\mathrm{EV}$ theory is domain specific.

\section{Expectancy-Value Theory and Multicultural Education}

As a result of increasing student diversity in the United States, multicultural education has become essential for four decades (Banks, 1981) to raising diversity awareness and promoting educational equity to ensure all students to learn. In examining the issue of cross-cultural relevance of the expectancyvalue theory, Sun and colleagues (2013) found that Chinese and American middle school students differed in their expectancy and value beliefs in physical education, suggesting the important cultural influence on expectancy-value motivation. Similarly, in developing a culturally framed application of Eccles et al.'s expectancy-value motivation model, Rogers (2008) found that race and ethnicity plays an important role in students' expectancy and value beliefs in gifted programs.

However, the utility of EV beliefs in multicultural education has yet to be explored. Although EV theory has been widely used in a plethora of fields including physical education (Grasten, 2016; Grasten, Watt, Hagger, Jaakkola, \& Liukkonen, 2015), music education (Burak, 2014), and STEM education (Lykegaard \& Ulriksen, 2016), no known studies to date have examined the utility of EV theory in multicultural education.

\section{Instrumentation Studies of Expectancy-Value Theory}

Despite the maturity and wide utility of the EV theory, the instrumentation is far less established and further validation studies are needed (Wigfield \& Eccles, 2000). In particular, there are several major flaws in the previous instrumentation studies of EV theory to capture expectancy and value beliefs. First, as noted by Eccles and colleagues (1983), much of the empirical work only focused on three of the task value constructs, namely, intrinsic value, attainment value, and/or utility value (Chouinard \& Roy, 2008), and cost has been largely ignored in empirical research (Flake et al., 2015). A recent study (Symes \& Putwain, 2016), for example, only focused on attainment value using an instrument with less than ideal internal reliability (Cronbach's $\alpha$ $=.65$ ). In another measurement study, Zhu et al. (2012) only found partial measurement invariance in physical education between elementary and middle school students. However, the scalar invariance is missing, cost was 
not studied, and it is unclear how the measurement would relate to the field of multicultural education. Measurement invariance is critical to the validation of an instrument as it requires that the association of items and the constructs/latent factors independent from group membership or measurement occasion (Mellenbergh, 1989; Van De Schoot, Schmidt, De Beuckelaer, Lek, \& Zondervan-Zwijnenburg, 2015). Flake and colleagues (2015) developed an instrument aimed at measuring the cost component of the task values. However, it is unknown how cost would fit in an integrative instrument as a subscale derived from the EV theory.

The cost of multicultural education is well documented in literature. For example, when taking a multicultural education class, students typically experience discomfort and anxiety, a typical emotional cost when their belief systems or unconscious biases are challenged (Jackson, 1999). Another typical cost is the cognitive load and workload students carry (Feldon, Callan, Juth, \& Jeong, 2019) in the course of multicultural education when they are expected to carry out diversity projects which involve a lot learning and uncomfortable social interactions as a result of their sensitive nature. Therefore, it is critical to examine cost as a major component in EV theory in multicultural education in the present study.

Second, there has been a lack of integrative instrumentation derived from the well-established comprehensive EV theory. No known instrument thus far is endowed with both expectancy and four value dimensions as posited by the EV theory (Eccles et al., 1983). In a recent study, Heyder et al. (2017) measured task values using single items representing three value components of the expectancy-value model, which only yielded less than ideal internal consistency for the combined measure (Cronbach's $\alpha=.75$ ). Heyder and colleagues (2017) not only left out the cost dimension, but also approached expectancy through assessing ability self-concept as an independent measure composed of four items. It was unknown whether using an integrative EV measure would have led to the same findings in their study. Similarly, in investigating high school students' competency beliefs and utility value, instead of using an integrative measure based on the EV theory, Chouinard and Roy (2008) used a subscale to assess the competence beliefs in mathematics and another subscale from a different measure to assess students' utility value.

Third, there has been a consistent discrepancy between the modern EV theory and its empirical structure. In one study involving 723 instrumental 
music students, McCormick and McPherson (2007) found out the structural model based on the EV theoretical framework had a poor fit to the data, and the four subjective task values and expectancy were all positively correlated with one another. In another study involving a sample of 2508 students at the end of secondary education, Trautwein and colleagues (2012) found high associations between expectancy and value beliefs and somewhat surprisingly, some of the relationships among the value components were weaker than those between the expectancy and value beliefs when the value components were supposed to be more similar to one another than expectancy as posited by the EV theory. The discrepant empirical finding once again raised concerns about the structural validity of the EV theory for the empirical data. More recently, Lykkegaard and Ulriksen (2016) questioned the validity of the EV model due to a discrepancy between the quantitative EV survey results and the qualitative interviews as well as a failure to detect significant changes in the students' educational choice processes, leading to a call for further validation studies of the EV model.

Fourth, as EV theory is domain specific (Wigfield \& Eccles, 2000), it is unclear whether the existing instruments measuring expectancy and value beliefs predominantly in other disciplines such as math (Lauermann \& Eccles, 2017), reading (Wigfield, 1997), and physical education (Zhu, Chen, \& Ennis, 2012) would hold in multicultural education. As expectancies for success, and various task values vary across disciplines (Durik et al., 2006; Wigfield, 1997) and races (Rodgers, 2008), it merits research to examine the underlying empirical structure of EV theory in the field of multicultural education.

\section{The Present Study}

In light of the scanty validation research of EV theory, the discrepancy between the EV theoretical framework and empirical models found in previous studies, and domain-specific nature of the EV theory, we endeavored to explore the empirical structure of the EV theory in the context of multicultural education by identifying common factors in college students' perceptions of the expectancy and value beliefs of multicultural education using Bayes exploratory factor analysis (BEFA). 


\section{Method}

\section{Participants}

A total of 187 college students with education majors in the Southeastern U.S. participated in a survey including Expectancy-Value Scale (EVS) and demographic items (all valid observations, with no missing values) as an option to earn course credit. Therefore, the convenience sampling method was employed. IRB guidelines were followed in the data collection process. The majority of participants were females $(N=153,81.82 \%)$, very typical of the education population makeup in the United States. Most of them identified as White $(N=118,63.10 \%)$, had a bachelor's degree $(N=99,52.94 \%)$, came from a hometown with a 10,000-50,000 population $(N=89,47.59 \%)$, and reported English as the first language $(N=178,95.19 \%)$. Overall, it is a rather homogenous sample with limited diversity, making multicultural education all the more important in the study context.

\section{Measures}

The Expectancy-Value Scale (EVS) contains four items measuring expectancy beliefs and 16 items measuring task values, including three items on attainment value, five items on intrinsic value, four items on utility value, and four items on cost. Most of the items derived from a previously published instrument in math and English (Trautwein et al., 2012), which only included two items each for cost and utility value subscales. We included four additional items (two items each for cost and utility value), suggested by Raubenheimer (2004), to ensure no fewer than three items per subscale. All items were adapted to make them subject specific (e.g., multicultural education). Exemplar items include "I have always been good at cross-cultural communications" (expectancy), "Diversity issues are important to me personally" (attainment value), "I'll need multicultural proficiency for my later life including my career" (utility value), "I enjoy learning about human diversity" (intrinsic value), and "The amount of time I spend on learning about human diversity keeps me from doing other things I would like to do" (cost). Participants responded on a seven-point scale from 1 ("not at all true of me") to 7 ("very true of me"). All negative items were reverse coded to allow consistency in directionality of all items. A higher score on the metric represents a higher expectancy or stronger value belief. All the 20 item scores of EVS from the participants were included in the analyses. Based on previous 
research results highlighting the participants' more positive responses to motivation (Yang, 2019), we utilized an unbalanced Likert scale skewing more towards the positive end to allow more variance.

\section{Bayesian Exploratory Factor Analysis}

The distribution of survey data was examined by calculating item response frequencies. This procedure allowed researchers to determine the prevalence of survey responses and to identify the survey items with the largest and the lowest proportions of favorable responses. No missing values were recorded; therefore, imputation procedures were not necessary.

The 20 survey items were then used as input for exploratory factor analysis (EFA). This procedure is commonly employed in social sciences to examine the structure of associations within a set of observed variables (Fabrigar \&Wegener, 2011) and to identify the latent dimensions, also referred to as common factors, that underlie the data (Hair, Anderson, Tatham, \& Black, 1998). In the current study, we used Mplus 7.4 (Muthén \& Muthén, 19982017) to conduct EFA with Bayes estimation (BEFA) and Geomin rotation. This estimation procedure does not require a multivariate normal distribution, provides accurate results with smaller samples, and permits the computation of models that are more complex than maximum likelihood (ML) (Asparouhov \& Muthén, 2010a; Heerwegh, 2014; Schmitt, 2011). Bayes estimation was also shown to outperform the mean- and variance-adjusted weighted least squares procedure with ordinal data (Asparouhov \& Muthén, 2010a; 2010b); it incorporates prior information thus increasing the accuracy of parameter estimates and reducing the number of Heywood solutions (Lee, 1981; Martin, \& McDonald, 1975; Mayekawa,1985). Geomin is an oblique rotation procedure; oblique procedures are employed when factors may correlate (Browne, 2001). If relationships may exist among factors, using an orthogonal rotation procedure may lead to a loss of information and biased estimates (Fabrigar, Wegener, MacCallum, \& Strahan, 1999).

We estimated and compared solutions with a different number of factors, and selected the optimal model based on the quality of the factor structure, interpretability of the factors, and goodness of fit indices. One of the goodness of fit indices used in this study is the posterior predictive $p$ value $(P P P)$, which indicates the extent to which the posterior distribution fits the data. The performance of $P P P$ in the Bayesian approach is stable and outperforms the chi-square goodness-of-fit test in the ML approach (Lee \& Song, 2004). The 


\section{Yang \& Mindrila - Expentacy-Value}

$P P P$ is estimated on every $10^{\text {th }}$ iteration and is further used to describe posterior probabilities. This probability estimate is based on a fit index $f$, which represents the likelihood ratio chi-square test of the null model against the proposed model (Muthén \& Asparouhov, 2010). Another goodness of fit index is the $95 \%$ confidence interval of the difference in the $f$ statistic between the real and the replicated data. When the middle point of this interval is close to zero, the $P P P$ value is close to .5 and the model has an excellent fit (Muthén $\&$ Asparouhov, 2010). Items with non-significant factor loadings at alpha $=.05$ and cross-loading items were sequentially deleted until an optimal factor structure was reached.

After reaching an optimal model, we estimated the location of each individual on the identified factors through the computation of Bayes plausible values. While frequentist estimation procedures such as ML or WLS may yield negative error variances with small samples, the Bayes estimator allows the computation of factor estimates by producing imputed plausible values. Bayes plausible values were shown to be more reliable than ML estimates with smaller samples and allow for a more accurate estimation of factor variances and correlations (Asparouhov \& Muthén, 2010c). A plot of mean plausible values was used to illustrate the distribution of individual scores on the identified factors. Further, mean plausible values were compared across demographic subgroups.

\section{Results}

Overall, survey items measuring the cost of multicultural education recorded lower proportions of favorable responses, whereas items measuring its perceived value recorded higher proportions of favorable responses. The positively worded survey item with the largest proportion of favorable ratings was "I think I'll be able to use what I learn about human diversity in other settings." ( $N=170,90.9 \%)$, suggesting the majority of the participants perceiving multicultural education as highly valuable. The positively worded item with the lowest level of agreement was "The amount of effort it will take to be good at cross-cultural communications is worthwhile to me. ( $\mathrm{N}=103$, $55.1 \%$ ). This result shows that only slightly over half of the participants were willing to put in the effort to learn about diversity issues, suggesting the relatively high cost of multicultural education. In contrast, the negatively worded item with the highest proportions of unfavorable ratings was "I am 
never good at communicating with people from different cultures $(N=123$, $65.8 \%$ ), indicating that most participants had considerable confidence in cross-cultural communication. The negatively worded item with the lowest level of disagreement was "I'd have to sacrifice a lot of free time to be good at cross-cultural communications" $(\mathrm{N}=65,34.8 \%)$, which, again, suggested the high perceived cost of multicultural education among the participants. Table 1 reports the distribution of responses on all survey items by aggregating ratings into three categories: a) untrue of me (1-2), b) neutral (3), and c) true of me (4-7).

Table 1.

Item Response Distribution

Untrue of
$\mathrm{Me}$
$(1-2)$

I think I'll be able to use what I learn about human diversity in other settings.

I think it is useful to learn about human diversity.

I enjoy learning about human diversity.

I am good at interacting with people from different cultures.

I'll need multicultural proficiency for my later life including my career.

Diversity issues are important to me personally.

The amount of effort it will take to $\begin{array}{llllll}3 & 1.6 \% & 14 & 7.5 \% & 170 & 90.9 \%\end{array}$

$\begin{array}{llllll}7 & 3.7 \% & 18 & 9.6 \% & 162 & 86.6 \%\end{array}$

$\begin{array}{llllll}5 & 2.7 \% & 20 & 10.7 \% & 162 & 86.6 \%\end{array}$

$\begin{array}{llllll}4 & 2.1 \% & 21 & 11.2 \% & 162 & 86.6 \%\end{array}$ be good at cross-cultural communications is worthwhile to me.

Good grades in diversity classes can be of great value to me later.

I am really keen to learn a lot in multicultural issues.

It is important to me personally to be proficient in cross-cultural communications.

$\begin{array}{rrrrrr}7 & 3.7 \% & 25 & 13.4 \% & 155 & 82.9 \% \\ 11 & 5.9 \% & 23 & 12.3 \% & 153 & 81.8 \% \\ 12 & 6.4 \% & 23 & 12.3 \% & 152 & 81.3 \% \\ & & & & & \\ 11 & 5.9 \% & 25 & 13.4 \% & 151 & 80.7 \%\end{array}$




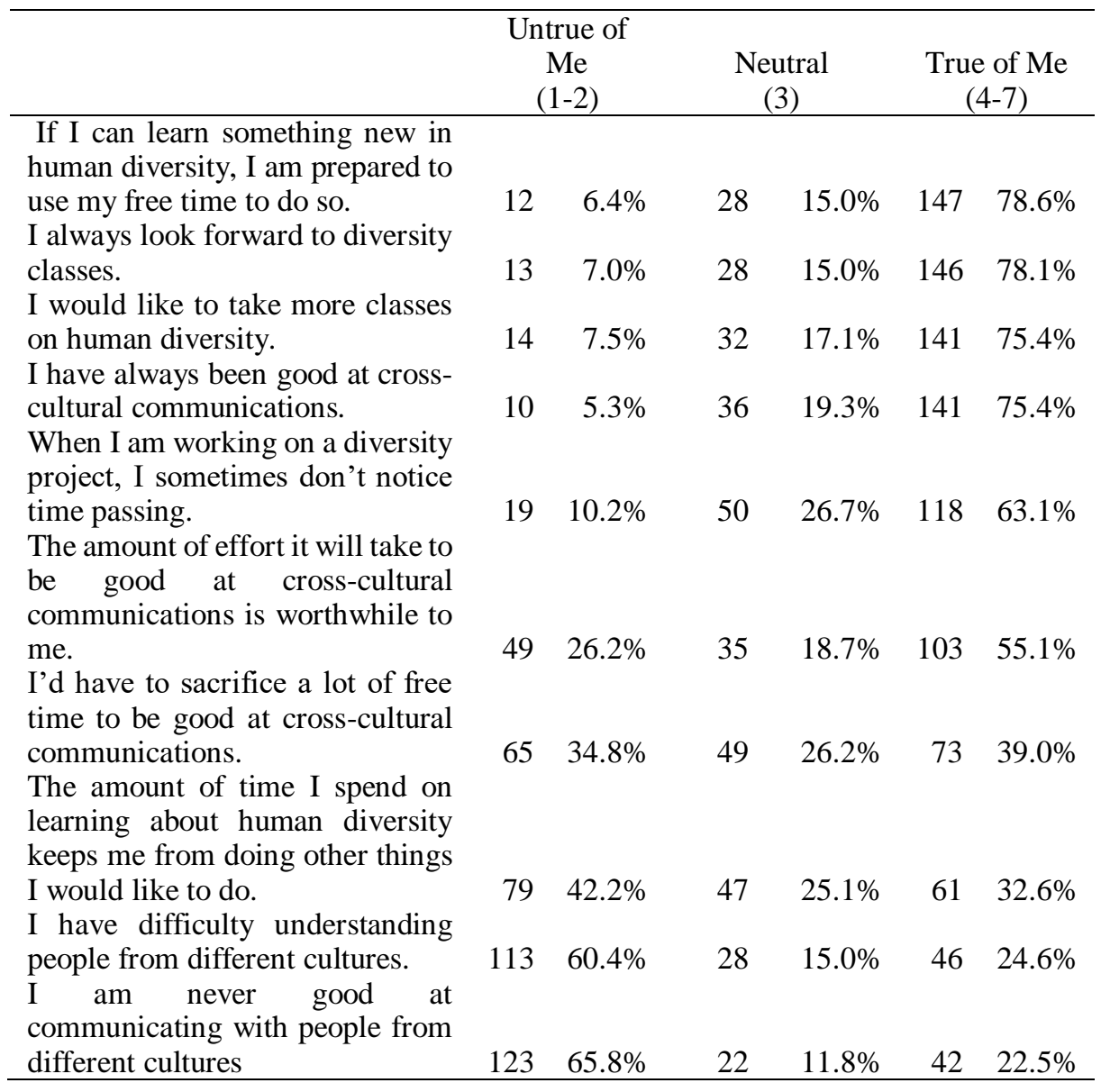

All seven-item response options were used for BEFA. Two eigenvalues were larger than one, and the scree plot suggested a three-factor solution; therefore, researchers estimated and compared models with one, two, and three factors. Cross-loading items were sequentially removed until a simple structure was reached. The optimal model included two factors and nine observed variables (Table 2). This solution had a PPP value of 0.49 and the $95 \%$ confidence interval for the difference between the observed and the replicated chi-square values was $(-30.53 ; 30.95)$, indicating excellent model fit. 
Table 2.

Matrix of Factor Loadings

\begin{tabular}{|c|c|c|}
\hline Item & F1 & F2 \\
\hline I think it is useful to learn about human diversity. & $.93 *$ & \\
\hline I enjoy learning about human diversity. & $.93 *$ & \\
\hline $\begin{array}{l}\text { It is important to me personally to be proficient in cross- } \\
\text { cultural communications. }\end{array}$ & $.90 *$ & \\
\hline Diversity issues are important to me personally. & $.89 *$ & \\
\hline $\begin{array}{l}\text { I am really keen to learn a lot in multicultural issues. } \\
\text { (attainment) }\end{array}$ & $.88 *$ & \\
\hline $\begin{array}{l}\text { If I can learn something new in human diversity, I am } \\
\text { prepared to use my free time to do so. }\end{array}$ & $.82 *$ & \\
\hline $\begin{array}{l}\text { I am never good at communicating with people from } \\
\text { different cultures. }\end{array}$ & & $.97 *$ \\
\hline $\begin{array}{l}\text { I have difficulty understanding people from different } \\
\text { cultures. }\end{array}$ & & $.80 *$ \\
\hline $\begin{array}{l}\text { The amount of time I spend on learning about human } \\
\text { diversity keeps me from doing other things I would like to } \\
\text { do. }\end{array}$ & & $.66^{*}$ \\
\hline
\end{tabular}

The first factor (F1 Value) included six items measuring students' value beliefs in learning about human diversity, with one item from the original Utility, two from Intrinsic, and three from Attainment Value subscales. Factor loadings ranged between .93 and .82 and were all statistically significant at alpha $=.05$ level. The marker item of this factor was "I think it is useful to learn about human diversity." The second factor (F2 Expectancy) included three items with statistically significant loadings ranging between .97 and .66 respectively, with two items from the original Expectancy and one from Cost subscale. These items refer to expectancy beliefs students hold in a diverse society, including their perceived challenges to understand and communicate with individuals from other cultures, and the amount of time taken away from them in learning about human diversity. The marker item of this factor was "I am never good at communicating with people from different cultures."

Mean plausible values ranged between -1.61 and $2.34(M=.00, S D=.91)$ for F1 Value, and between -2.85 and $1.64(M=.02, S D=.94)$ for F2 Expectancy. The distribution of F1 and F2 mean plausible values is illustrated in Figure 1. The two factors had a small positive correlation $(r=0.22, p<.01)$. 


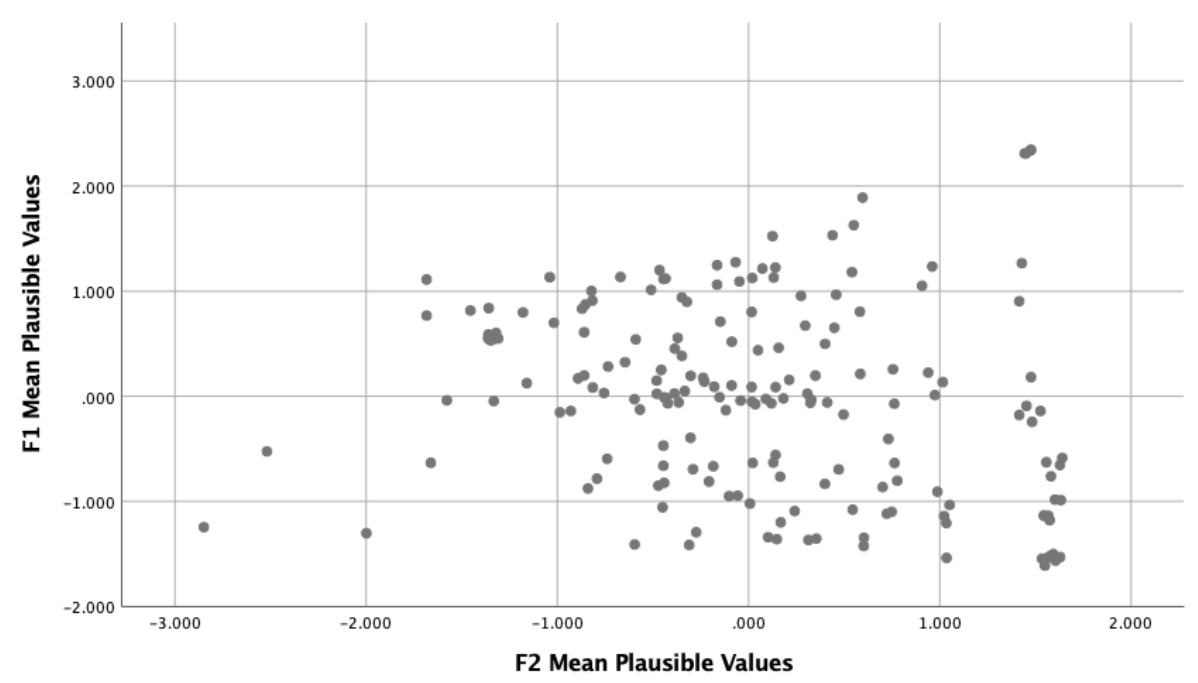

Figure 1. Distribution of mean plausible values on F1 and F2

Using the 1.5xIQR rule, four cases with very high scores on F1 and two cases with very low scores on F2 were identified (Browne, 2001). When these cases were removed, the factor correlation increased to $r=.42, \mathrm{p}<.001$. As indicated in Table 3, mean plausible values did not differ significantly by gender, ethnicity, or hometown size; however, students with a Master's or Doctoral degree had significantly lower means on F2 Expectancy $\left(t_{(47.727)}=-2.90, p<.01\right)$ than respondents with a Bachelor's degree, meaning those who obtained graduate degrees reported less difficulty, more confidence, and more willingness in diversity than those at undergraduate level. 
Table 3

Mean Plausible Values by Demographic Subgroups

\begin{tabular}{|c|c|c|c|c|}
\hline & \multicolumn{2}{|c|}{ F1 } & \multicolumn{2}{|c|}{ F2 } \\
\hline & $M$ & $S D$ & $M$ & $S D$ \\
\hline \multicolumn{5}{|l|}{ Gender } \\
\hline Male $(\mathrm{N}=33)$ & -.05 & .92 & .00 & .91 \\
\hline Female $(\mathrm{N}=153)$ & .02 & .91 & .03 & .96 \\
\hline$t_{(\mathrm{df}), p}$ & \multicolumn{2}{|c|}{$t_{(46.400)}=-.36, p=.72$} & \multicolumn{2}{|c|}{$t_{(88.614)}=-.16, p=.88$} \\
\hline \multicolumn{5}{|l|}{ Hometown size } \\
\hline Below 10,000 $(\mathrm{N}=42)$ & .00 & .88 & .05 & .95 \\
\hline $10,000-50,000(\mathrm{~N}=89)$ & .04 & .94 & .03 & .96 \\
\hline Above $50,000(\mathrm{~N}=55)$ & -.05 & .90 & -.02 & .94 \\
\hline$F_{(\mathrm{df})}, p$ & \multicolumn{2}{|c|}{$F_{(2,183)}=.18, p=.84$} & \multicolumn{2}{|c|}{$F_{(2,183)}=.08, p=.92$} \\
\hline \multicolumn{5}{|l|}{ Ethnicity } \\
\hline Caucasian $(\mathrm{N}=118)$ & -.03 & .83 & -.24 & .87 \\
\hline Minority $(\mathrm{N}=68)$ & .06 & 1.04 & .10 & 1.06 \\
\hline$t_{(\mathrm{df}), p}$ & \multicolumn{2}{|c|}{$t_{(116.612)}=-.66, p=.51$} & \multicolumn{2}{|c|}{$t_{(118.529)}=-.81, p=.42$} \\
\hline \multicolumn{5}{|l|}{ Highest Degree } \\
\hline Bachelor's ( $\mathrm{N}=99)$ & -.09 & .95 & .07 & .98 \\
\hline Master or Doctoral $(\mathrm{N}=27)$ & .12 & .82 & -.48 & .83 \\
\hline$t_{(\mathrm{df}), p}$ & \multicolumn{2}{|c|}{$t_{(46.857)}=1.15, p=.26$} & \multicolumn{2}{|c|}{$t_{(47.727)}=-2.90, p<.01$} \\
\hline
\end{tabular}

\section{Discussion}

In this study, we probed the underlying structure of the modern expectancyvalue $(\mathrm{EV})$ theory in multicultural education in response to calls for more validation studies on the constructs of expectancy and value beliefs as an important issue for further research (Wigfield \& Eccles, 2000). Although the EV theory posits five dimensions including expectancy of success and four types of task values including intrinsic value, attainment value, utility value and cost, the BEFA results in our study suggests a two-factor model may be more appropriate in multicultural education, which conflicted with previous results about the theoretical distinctions of the three task values in the Eccles et al. model (Wigfield \& Eccles, 2000). Most of the value items from the original EV scale loaded on one single value factor instead of different value subscales in our study. It is plausible since previous research results have 
shown relatively high correlations among the four value components that have often been incorporated into a general value scale (e.g., Eccles et al., 1993).

The discrepancy between the factor solution in the study and the fivedimension model of EV theory (Eccles et al., 1983; Wigfield \& Eccles, 2000) may be a result of several elements. First, as Eccles and colleagues have argued, EV model is domain specific, which was supported by our study results. As Wigfield (1997) held that what matters in math may be totally different from reading, the values of learning about math or English may be very different from learning about human diversity. As multicultural proficiency is a lot harder to assess (e.g., Prieto, 2012) than learning outcomes in other disciplines such as math or English proficiency, expectancy of success in interacting with diverse individuals may be more elusive and hence less salient than the values of learning about human diversity. Instead, value beliefs have been found to be more potent than expectancy beliefs in predicting some motivation variables including effort or choice (Nagengast et al., 2011; Trautwein et al., 2012), echoing the conceptual differentiation of expectancy and value beliefs as two factors found in our study: value and expectancy. It partially supported the modern EV theory which posits that expectancy and value beliefs of the tasks are two primary motivating factors (Eccles \& Wigfield, 2002). Given the synergistic predictive power of expectancy and value beliefs in a previous study (Trautwein et al., 2012), it merits more research on the structural validity of the EV model in multicultural education.

Second, the current five-dimension EV model may have complicated the construct of motivation in multicultural education. The more parsimonious fit of the two-factor model from the BEFA results of the present study suggests that perhaps motivation for multicultural education should be considered as a two-factor construct, value and expectancy. Rather than focusing on all the five dimensions of the theoretical EV model, it may be more helpful for teacher educators to focus on the values of learning about student diversity and the support needed to help improve the expectancy beliefs in interacting with diverse students. According to Flakes and colleagues (2015), it could be achieved by improving the efficacy beliefs or lowering the difficulty level of learning, which may help reduce the amount of task effort or outside effort. Additionally, providing emotional support (Wang, 2008) may be a critical way to help motivate multicultural learning which inevitably involves overcoming negative emotions as one challenges one's own biases, beliefs, and faces what 
had happened in history due to prejudice and discrimination. Resonating with a previous study (Trautwein et al., 2012) which called for the need to reexamine EV instrumentation, our study results of the distinct Bayesian model suggest a need for more research inquiry to examine the structural validity of the EV theory and the instrument development and validation in multicultural education.

Third, we found positive associations between value and expectancy, resonating with previous studies showing positive associations between expectancy and value beliefs (e.g., Eccles et al., 1998; Trautwein et al., 2012). Although somewhat unexpectedly, one cost item loaded together with two expectancy items on expectancy factor, it is consistent with a previous study result showing that some of the associations among value beliefs were weaker than those between value and expectancy beliefs (Trautwein et al., 2012), suggesting the need for further studies to attend to the nature of the value and expectancy constructs in improving their theoretical clarity. However, our results partly support the previous empirical results showing cost and value as distinct constructs (Mosyjowski et al., 2017).

Fourth, by examining the distribution of plausible values, the current study examined potential group differences in their value and expectancy perceptions of student diversity. Unexpectedly, we did not find a significant gender effect on the participants' expectancy or value beliefs in multicultural education, conflicting with previous research indicating that boys and girls differ in their competency beliefs in math (Chouinard \& Roy, 2008; Fredricks $\&$ Eccles, 2002). However, we found that education made a difference: participants with masters' and doctor's degrees reported higher expectancy beliefs in interacting with student diversity, consistent with a previous study result (Yang, 2018).

Overall, the BEFA findings on EVS developed from EV theory produced a two-factor model compared to the five-dimensional models of EV theory proposed by Eccles and colleagues (e.g., Eccles et al., 1983; Wigfield \& Eccles, 2000). The discrepancy between our BEFA results and the theoretical EV model calls for further psychometric studies before a definitive conclusion can be made to reconsider the empirical structure of EV theory in a more simplified and parsimonious fashion in multicultural education. The significant difference in expectancy beliefs among participants based on the highest degrees attained confirmed the importance of higher education on improving efficacy beliefs in cross cultural communication. Future research 


\section{Yang \& Mindrila - Expentacy-Value}

may examine whether the degree of higher education may actually lead to higher cultural competence beyond the efficacy beliefs.

\section{Limitations and Future Directions}

The failure of the BEFA results of the current study to fully support the EV model (Eccles et al., 1983) raised concerns of understanding and operationalizing expectancy and value beliefs in multicultural education. The two-factor solution suggests a more parsimonious model for teacher educators to understand what motivates students and what is essential in promoting multicultural education. More studies are needed to probe the underlying structure of the modern five-dimension EV model in multicultural education. Further, as previous research (e.g., Flakes et al., 2015; Mosyjowski et al., 2017) indicates different types of cost such as financial cost, balance cost, emotional cost, etc., future studies may incorporate more cost items to the measurement and test if cost factor may be present in the empirical model.

The positive low factor correlations between value and expectancy disclosed in the BEFA results posed an intriguing question: which one should teacher educators highlight more in multicultural educations to motivate students, promoting the value of learning about diversity or improving expectancy beliefs? Future research should endeavor to test the two factors through confirmatory factor analyses and replicate to bigger samples before we can reach a definitive conclusion. Only when we know what's essential in motivating students in multicultural education, will we as teacher educators be better able to motivate students in multicultural education and help create a more inclusive society. As a previous study suggests that the associations between expectancy and value beliefs within a domain increases over time (Wigfield et al., 1997), future research can also investigate if age is a factor in the relationship between expectancy and value beliefs in multicultural education.

Last but not least, future research should link the value and expectancy factors of multicultural education with cultural competence and related outcomes to examine the criterion-related validity. Previous research results showed that expectancy- and value-related constructs predicted outcomes differently. In particular, expectancy beliefs have been shown to particularly predict performance and achievements, and value beliefs are more closely associated with choice, effort, and persistence (e.g., Jones et al., 2010; 
Nagengast et al., 2011; Trautwein \& Lu“dtke, 2007; Wigfield et al., 1997). In examining academic-track boys' underachievement in language grades, Heyder and colleagues (2017) challenged the stereotypical belief that boys' lower grades are due to lower verbal aptitude and disclosed the critical roles of motivational beliefs such as parental perceptions. In light of this, future research can examine whether students' expectancy beliefs in multicultural education predict their cultural competence and whether their value beliefs predict their choices and efforts in the process of learning about human diversity. Further, Chouinard et al. (2007) found that effort in mathematics is mainly explained by competence beliefs, valuing of mathematics by parental support, and competency beliefs by teacher support. Future research can investigate the antecedents and consequences of expectancy and value beliefs of multicultural education and examine whether the associations found in mathematics would translate to the field of multicultural education.

\section{Significance of the Study}

Overall, although we found partial conceptual support of EV theory into two distinct factors in multicultural education: value and expectancy (Eccles \& Wigfield, 2002), we did not find empirical support for the different types of values in line with the EV theory (Wigfield \& Eccles, 2000). Our study results revealed the importance of boosting both students' perceived values and expectancy beliefs in multicultural education to improve student motivation. In a study involving 173 first-semester students, Cole and colleagues (2011) found that students taking diversity courses were more aware of white privilege and less likely to deny the existence of blatant racism at the end of a semester than those in a comparison course that is not diversity related, confirming the value of multicultural education. However, due to the various emotional challenges students have to overcome as a result of cognitive dissonance, Jackson (1999) revealed student resistance in the learning process, suggesting the low expectancy beliefs in students. As such, understanding students' value and expectancy beliefs in multicultural education will better equip educators in highlighting the benefits of multicultural education and lifting students' efficacy beliefs in the difficult learning process that is challenging and emotionally charging. Resonating with previous results (McCormick \& McPherson, 2007; Trautwein et al., 2012), the findings of our study suggest a need for further research replicated to larger and more diverse 
samples to further examine the structural validity of the EV theory in multicultural education.

\section{References}

Abraham, J., \& Barker, K. (2015). An expectancy-value model for sustained enrolment intentions of senior secondary physics students. Research in Science Education, 45(4), 509. doi:10.1007/s11165-014-9434-X

Andersen, L., \& Ward, T. J. (2014). Expectancy-value models for the STEM persistence plans of ninth-grade, high-ability students: A comparison between Black, Hispanic, and White Students. Science Education, 98(2), 216. doi:10.1002/sce.21092

Asparouhov, T., \& Muthén, B. (2010a). Bayesian analysis of latent variable models using Mplus. Technical Report. Version 4. Retrieved from http://www.statmodel.com/download/BayesAdvantages 18. pdf

Asparouhov, T., \& Muthén, B. (2010b). Bayesian analysis using Mplus: Technical implementation (Technical appendix). Los Angeles, CA: Muthén \& Muthén. Retrieved from http://www.statmodel.com/download/BayesAdvan tages 18.pdf

Asparouhov, T., \& Muthén, B. (2010c). Plausible values for latent variables using Mplus. Unpublished. Accessed at: http://www. statmodel.com/download/ Plausible.pdf

Banks, J. A. (1981). Education in the 80s: Multiethnic education. Washington, D.C: National Education Association.

Banks, C., \& Banks, J. (1995). Equity pedagogy: An essential component of multicultural education. Theory into Practice, 34, 152-158. doi: 10.1080/00405849509543674

Bembenutty, H. (2008). The last word: The scholar whose expectancy-value theory transformed the understanding of adolescence, gender differences, and achievement: An Interview with Jacquelynne S. Eccles. Journal of Advanced Academics, 19(3), 531-550. doi: 10.4219/jaa-2008-811

Browne, M. W. (2001). An overview of analytic rotation in exploratory factor analysis. Multivariate Behavioral Research, 36(1), 111-150. doi: 10.1207/S15327906MBR3601_05

Burak, S. (2014). Motivation for instrument education: A Study with the 
perspective of expectancy-value and flow theories. Eurasian Journal of Educational Research, 55, 123-136. doi: 10.14689/ejer.2014.55.8 Chouinard, R., Karsenti, T., \& Roy, N. (2007). Relations among competence beliefs, utility value, achievement goals, and effort in mathematics. The British Journal of Educational Psychology, 77, 501-517. doi: 10.1348/000709906X133589

Chouinard, R., \& Roy, N. (2008). Changes in high-school students' competence beliefs, utility value and achievement goals in mathematics. The British Journal of Educational Psychology, 78, 3150. doi: 10.1348/000709907X197993

Cole, E. R., Case, K. A., Rios, D., \& Curtin, N. (2011). Understanding what students bring to the classroom: Moderators of the effects of diversity courses on student attitudes. Cultural Diversity \& Ethnic Minority Psychology, 17(4), 397-405. doi: 10.1037/a0025433

DiStefano, C., Zhu, M., \& Mindrila, D. (2009). Understanding and using factor scores: Considerations for the applied researcher. Practical Assessment, Research \& Evaluation, 14(20), 1-11. doi: 10.7748/nr2006.10.14.1.71.c6011

Eccles (Parsons) J, Adler TF, Futterman R, Goff SB, Kaczala CM, et al. (1983). Expectancies, values, and academic behaviors. In Achievement and Achievement Motivation, ed. JT Spence, pp. 75146. San Francisco: Freeman.

Eccles, J., \& Wigfield, A. (2002). Motivational beliefs, values and goals. Annual Review of Psychology. 53, 109-132. doi: 10.1146/annurev.psych.53.100901.135153.

Eccles, J. S., Wigfield, A., Harold, R., \& Blumenfeld, P. (1993). Age and gender differences in children's self and task perceptions during elementary school. Child Development, 64, 830 - 847. doi:10.2307/1131221

Eccles, J. S., Wigfield, A., \& Schiefele, U. (1998). Motivation to succeed. In W. Damon \& N. Eisenberg (Eds.), Handbook of child psychology (5th ed., Vol. 3, pp. 1017-1095). New Jersey: Wiley.

Fabrigar, L. R., \& Wegener, D. T. (2011). Exploratory factor analysis. Oxford University Press. doi: 10.1093/acprof:osobl/9780199734177.001.0001 
Fabrigar, L. R., Wegener, D. T., MacCallum, R. C., \& Strahan, E. J. (1999). Evaluating the use of exploratory factor analysis in psychological research. Psychological methods, 4(3), 272. doi:1082-989X/99/S3.00

Feldon, D., Callan, G., Juth, S., \& Jeong, S. (2019). Cognitive load as motivational cost. Educational Psychology Review, 31. doi: 10.1007/s10648-019-09464-6.

Flake, J. K., Barron, K. E., Hulleman, C., McCoach, B. D., \& Welsh, M. E. (2015). Measuring cost: The forgotten component of expectancyvalue theory. Contemporary Educational Psychology, 41, 232-244. doi: 10.1016/j.cedpsych.2015.03.002

Fredricks, J. A., \& Eccles, J. S. (2002). Children's competence and value beliefs from childhood through adolescence: Growth trajectories in two male-sex typed domain. Developmental Psychology, 38(4), 519533. doi: 10.1037/0012-1649.38.4.519

Gagne, P., \& Hancock, G. R. (2006). Measurement model quality, sample size, and solution propriety in confirmatory factor models. Multivariate Behavioral Research,41(1), 65-83. doi:10.1207/s15327906mbr4101_5

Guay, F. (2016). The virtue of culture in understanding motivation at school: Commentary on the special issue on culture and motivation. British Journal of Educational Psychology, 86(1), 154-160. doi: 10.1111/bjep. 12105

Guo, J., Parker, P. D., Marsh, H. W., \& Morin, A. S. (2015). Achievement, motivation, and educational choices: A longitudinal study of expectancy and value using a multiplicative perspective. Developmental Psychology, 51(8), 1163-1176. doi:10.1037/a0039440

Hair, J. F., Black, W. C., Babin, B. J., Anderson, R. E., \& Tatham, R. L. (1998). Multivariate data analysis (Vol. 5, No. 3, pp. 207-219). Upper Saddle River, NJ: Prentice hall.

Heerwegh, D. Small sample Bayesian factor analysis. Retrieved from: http://www.phusewiki.org/docs/ Conference\%202014\%20SP\%20Papers/SP03.pdf

Heyder, A., Kessels, U., \& Steinmayr, R. (2017). Explaining academic-track boys' underachievement in language grades: Not a lack of aptitude but students' motivational beliefs and parents' perceptions? British 
Journal of Educational Psychology, 87(2), 205-223. doi: 10.1111/bjep.12145

Jackson, L. C. (1999). Ethnocultural resistance to multicultural training: Students and faculty. Cultural Diversity \& Ethnic Minority Psychology, 5(1), 27-36. doi: 10.1037/1099-9809.5.1.27

Jones, B. D., Paretti, M. C., Hein, S. F., \& Knott, T. W. (2010). An analysis of motivation constructs with first-year engineering students: Relationships among expectancies, values, achievement, and career plans. Journal of Engineering Education, 99(4), 319-336. doi: 10.1002/j.2168-9830.2010.tb01066.x

Lauermann, F., Tsai, Y., \& Eccles, J. S. (2017). Math-related career aspirations and choices within Eccles et al.'s expectancy-value theory of achievement-related behaviors. Developmental Psychology, 53(8), 1540-1559. doi:10.1037/dev0000367

Lee, S.Y. (1981). A Bayesian approach to confirmatory factor analysis. Psychometrika, 46, 153-160. doi: 10.1007/bf02293896

Lee, S.Y., \& Song, X.Y. (2004). Evaluation of the Bayesian and Maximum Likelihood approaches in analyzing structural equation models with small sample sizes. Multivariate Behavioral Research, 39(4), 653686. doi: 10.1207/s15327906mbr3904_4

Lykkegaard, E., \& Ulriksen, L. (2016). Choices and changes: Eccles' expectancy-value model and upper-secondary school students' longitudinal reflections about their choice of a STEM education. International Journal of Science Education, 38(5), 701-724. doi:10.1080/09500693.2016.1156782

MacCallum, R. C., Widaman, K. F., Zhang, S., \& Hong, S. (1999). Sample size in factor analysis. Psychological methods, 4(1), 84. doi: 10.1037/1082-989X.4.1.84

Martin, J.K. \& McDonald, R.P. (1975). Bayes estimation in unrestricted factor analysis: A treatment of Heywood cases. Psychometrika, 40, 505-517. doi: $10.1007 /$ bf02291552

Masson, A., Klop, T., \& Osseweijer, P. (2016). An analysis of the impact of student-scientist interaction in a technology design activity, using the expectancy-value model of achievement related choice. International Journal of Technology \& Design Education, 26(1), 81. doi:10.1007/s10798-014-9296-6 
Mayekawa, S. (1985). Bayesian factor analysis (ONR Technical Report No. 85-3). Iowa City: Cada Research Group, University of Iowa.

McCormick, J., \& McPherson, G. (2007). Expectancy-value motivation in the context of a music performance examination. ERA - Humanities \& Creative Arts. 11. 37-52. doi:10.1177/10298649070110S203.

Mellenbergh, G. J. (1989). Item bias and item response theory. International Journal of Educational Research, 13, 127-143. doi: 10.1016/08830355(89)90002-5

Mosyjowski, E. A., Daly, S. R., Peters, D. L., Skerlos, S. J., \& Baker, A. B. (2017). Engineering PhD returners and direct-pathway students: Comparing expectancy, value, and cost. Journal of Engineering Education, 106(4), 639-676. doi: 10.1002/jee.20182

Mundfrom, D. J., Shaw, D. G., \& Ke, T. L. (2005). Minimum sample size recommendations for conducting factor analyses. International Journal of Testing, 5(2), 159-168. doi: 10.1207/s15327574ijt0502_4 Muthén, B., \& Asparouhov, T. (2010). Bayesian structural equation modeling: A more flexible representation of substantive theory. Psychological Methods, 17(3), 313. doi: 10.1037/a0026802

Muthén, L.K., \& Muthén, B.O. (1998-2017). Mplus user's guide ( $8^{\text {th }}$ ed.). Los Angeles, CA: Muthén \& Muthén .

Nagengast, B., Marsh, H. W., Scalas, L. F., Xu, M., Hau, K.-T., \& Trautwein, U. (2011). Who took the "X" out of expectancy-value theory? A psychological mystery, a substantive-methodological synergy, and a cross-national generalization. Psychological Science, 22, 1058-1066. doi:10.1177/0956797611415540

Phoon, H.S., Abdullah, M. N. L. Y, \& Abdullah, A.C. (2013). Multicultural early childhood education: Practices and challenges in Malaysia. The Australian Educational Researcher, 40, 615-632. doi: 10.1007/s13384-013-0120-1

Prieto, L. R. (2012). Initial factor analysis and cross-validation of the Multicultural Teaching Competencies Inventory. Journal of Diversity in Higher Education, 5(1), 50-62. doi: 10.1037/a0026199

Raubenheimer, J. (2004). An item selection procedure to maximize scale reliability and validity. Journal of Industrial Psychology, 30(4), 5964. doi: 10.4102/sajip.v30i4.168.

Rodgers, K. A. (2008). Racial identity, centrality and giftedness: An expectancy-value application of motivation in gifted African 
American students. Roeper Review, 30(2), 111-120. doi:10.1080/02783190801955103

Rogers-Sirin, L., \& Sirin, S. R. (2009). Cultural competence as an ethical requirement: Introducing a new educational model. Journal of Diversity in Higher Education, 2(1), 19-29. doi: 10.1037/a0013762

Schmitt, T. A. (2011). Current methodological considerations in exploratory and confirmatory factor analysis. Journal of Psychoeducational Assessment, 29(4), 304-321. doi: 10.1177/0734282911406653

Sleeter, C. E. (2018). Multicultural education past, present, and future: Dialogue and power-sharing. International Journal of Multicultural Education 20(1), 5- 20. doi: 10.18251/ijme.v20i1.1663

Sun., H., Ding, H., \& Chen A. (2013). Nothing but being there matters: Expectancy-value motivation between U.S. and Chinese middle school students. International Education, 42(2), 7-20.

Symes, W., \& Putwain, D. W. (2016). The role of attainment value, academic self-efficacy, and message frame in the appraisal of value-promoting messages. The British Journal of Educational Psychology, 86(3), 446-460. doi:10.1111/bjep. 12117

Trautwein, U., \& Lu“dtke, O. (2007). Students' self-reported effort and time on homework in six school subjects: Between-student differences and within-student variation. Journal of Educational Psychology, 99, 432-444. doi:10.1037/0022-0663.99.2.432

Trautwein, U., Marsh, H. W., Nagengast, B., Lüdtke, O., Nagy, G., \& Jonkmann, K. (2012). Probing for the multiplicative term in modern expectancy-value theory: A latent interaction modeling study. Journal of Educational Psychology, 104(3), 763-777. doi:10.1037/a0027470

United States Census Bureau. (2017a). 2016 American Community Survey 1Year Estimates. Retrieved from https://factfinder.census.gov/faces/tableservices/jsf/pages/productvie w.xhtml?pid=ACS_16_1YR_S1601\&prodType=table

United States Census Bureau. (2017b). Current Population Survey, 19952016. Retrieved from https://www.census.gov/data/tables/timeseries/demo/school-enrollment/cps-historical-time-series.html 
80 Yang \& Mindrila - Expentacy-Value

Van De Schoot, R., Schmidt, P., De Beuckelaer, A., Lek, K., \& ZondervanZwijnenburg, M. (2015). Editorial: Measurement invariance. Measurement Invariance, 5. doi: 10.3389/fpsyg.2015.01064

Wang, H. (2008). "Red eyes": Engaging emotions in multicultural education. Multicultural Perspectives, 10(1), 10-16. doi: 10.1080/15210960701869330

Wigfield, A., Eccles, J. S., Yoon, K. S., Harold, R. D., Arbreton, A. J. A., Freedman-Doan, C., \& Blumenfeld, P. C. (1997). Change in children's competence beliefs and subjective task values across the elementary school years. A 3-year study. Journal of Educational Psychology, 89, 451-469. doi:10.1037//0022-0663.89.3.451

Yang, Y. (2019). An exploratory value-cost approach in predicting college students' achievement goals in multicultural education. International Journal of School \& Educational Psychology. doi: 10.1080/21683603.2019.1650859

Yang, Y. (2018). Praxis or knowledge? An attributional perspective in multicultural teacher education. New York, NY: NOVA.

Zan, G., Lee, A. M., \& Harrison Jr., L. (2008). Understanding students' motivation in sport and physical education: From the expectancyvalue model and self-efficacy theory perspectives. Quest, 60(2), 236. doi: $10.1080 / 00336297.2008 .10483579$

Zhu, X., Sun, H., Chen, A., \& Ennis, C. (2012). Measurement invariance of Expectancy-Value Questionnaire in physical education. Measurement in Physical Education \& Exercise Science, 16(1), 41. doi:10.1080/1091367X.2012.639629 
Yann Yang is associate professor in Educational Psychology at the University of West Georgia, United States of America.

Diana Mindrila is associate professor in Educational Research at the University of West Georgia, United States of America.

Contact Address: 1601 Maple St., Ed Annex Room 149, Carrollton, GA 30118 U.S.A. Tel: +1(678)839-6133. Email: yyang@westga.edu 